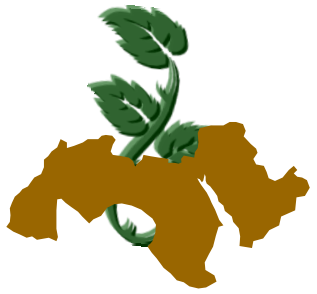

\title{
BIOEFFECTS OF THE ENTOMOPATHOGENIC FUNGI BEAUVERIA BASSIANA (BALS.) ON MUSHROOM FLY BRADYSIA OCELLARIS (COMS.) (DIPTERA: SCIARIDAE)
}

\author{
Dawalibi $^{1}$, W.A.M.; S.M.T. Khoja ${ }^{1}$; M.M. Abou- Shaar ${ }^{2}$ and N.A. Kaake ${ }^{2}$ \\ 1. General Commission for Scientific Agricultural Research (Gcsar), Aleppo, Syria \\ 2. Faculty of Agriculture, Aleppo University, Aleppo, Syria
}

Keywords: Beauveria bassiana, Bradysia ocellaris. Mushroom fly

\begin{abstract}
Laboratory experiments were carried out to determine the bioeffects of an isolate of entomopthogenic fungi Beauveria bassiana (Bals.) and Biofly a commercial product of $B$. bassiana, on the $1^{\text {st }}$ instar larvae of mushroom fly, Bradysia ocellaris (coms). The bioactivity of B. bassiana was tested, using five concentrations of B. bassiana on some biological criteria of the mushroom fly, by calculating $\mathrm{LC}_{50}$ values after three and seven days of treatment. Results indicated that the mortality rates percentage increased with the increase of the concentrations used and the period after treatment. The highest percentage of mortality occurred within the first seven days following treatment. Statistical analysis of the obtained larval-pupal and adults period and weight revealed significant differences between treated and nontreated insects.
\end{abstract}

\section{INTRODUCTION}

In recent years, an increasing consumer demand for commercial mushroom products, as natural healthy foods has raised concerns about problems in mushroom production. Mushroom flies proved to be a serious pest facing mushroom growers (Finley et al 1984; Ishitani, et al 1997; Jess and Kilpatrick, 2000). The existing control measures against the fly still rely on chemical insecticides, which are not always appropriate. The use of pathogens may offer an environmentally sound method for the management of insect pests. Hyphomycete fungi are the most promising candidates (Prior, 1990).

Entomopathogenic fungi have been intensively studied as potential microbial insecticides (Gillespie 1988; Ferron et al 1991; Malsam et al 1998). Beauveria spp. has been investigated because of their ability to infect a wide range of insects. There are more than 400 species recorded as entomopathogenic fungi, from which only about 20 species have the potential to be used in microbial control of insect pests (Zimmerman, 1986).

The present work was carried out with the endeavor of evaluating the bioassay of Beauveria bassiana against the mushroom fly Bradysia ocellaris and to evaluate the bioactivity effect of Beauveria bassiana on some biological criteria of mushroom fly B. ocellaris.

\section{MATERIALS AND METHODS}

\section{Rearing mushroom fly}

Mushroom fly $B$. ocellaris was reared under laboratory condition at $23 \pm 1^{\circ} \mathrm{C}$ in ventilated plastic boxes $(28 \times 16 \times 9 \mathrm{~cm})$ filled with peat to a depth of about $5 \mathrm{~cm}$. About $10 \mathrm{ml}$ of water was mixed into the peat so that the mixture will remain moist to the touch and $1 \mathrm{~g}$ of wheat was distributed over the surface of peat as food source for the larvae. Adult mushroom flies $B$. ocellaris were put into the boxes and an additional $1 \mathrm{~g}$ of wheat grain was added every 3-4 days together with a cotton plug soaked in a $20 \%$ glucose to boost the number of eggs laid by females (Gouge 1994).

\footnotetext{
*Bradysia ocellaris was identified at the Department of Entomology in the Natural History Museum, London
}

(Received September 26, 2007)

(Accepted November 10, 2007) 
Two ELISA dishes were used for each treatment; every well of the bottom ELISA dish contained one wheat grain covered with spawn and one larvae of Bradysia ocellaris. The dishes were treated with different concentrations of $B$. bassiana $\left(10^{2}, 10^{3}, 10^{4}, 10^{5}, 10^{6}\right)$ conidia/ml, control treatment was treated with $0.1 \%$ Tween alone. In the well of the upper dish, a piece of cotton moistened with similar concentrations of $B$. bassiana and with sterilized water $+0.1 \%$ Tween 80 in the control treatment. Dishes were then put inside moist boxes containing moistened filter paper. The dishes were incubated at $23 \pm 1^{\circ} \mathrm{C}, 70 \pm 5 \% \mathrm{RH}$ and $24 \mathrm{~h}$ (dark). Mortality was recorded daily for about 14 days. Dead larvae were removed and maintained in a moist chamber to allow for fructification of the relevant fungus

\section{Bioassay experiments}

In this study, the entomopathogenic fungus $B$. bassiana, (S1), isolated from adults of Eurygaster integriceps pest and (Biofly), a commercial product of B.bassiana, were assayed for their bioinsecticidal activities against $1^{\text {st }}$ instar larvae of the $B$. ocellaris. The first isolate was grown and maintained on Potato Dextrose Antibiotic Agar (PDAA) and incubated in the dark for 20 days at $25 \pm 1^{\circ} \mathrm{C}$ for the actual bioassay, conidial suspensions of each of the isolates were prepared by scraping conidia from the surface of 20 days old cultures in $0.1 \%$ Tween 80 . The suspension was diluted in sterilized water $+0.1 \%$ Tween 80 to get suspensions ranging from $1 \times 10^{2}$ to $1 \times 10^{6}$ conidia / $\mathrm{ml}$. A total of $10 \mathrm{ml}$ suspension was prepared for each dilution.

\section{Larvae treatment}

The experiments were carried out under laboratory conditions of $23 \pm 1^{\circ} \mathrm{C}$ and $80 \pm 5 \mathrm{RH}$. Five concentrations of $\mathrm{B}$. bassiana $10^{2}, 10^{3}, 10^{4}, 10^{5}$ and $10^{6}$ conidia/ml were used. In all experiments percentage mortality was calculated after 3, 5, 7, 10 , and 14 days. Percentage of mortality of each treatment was corrected use using Abbott's formula (Abbott, 1925). The percentages of mortality were statistically computed according to (Finney, 1952) and computed mortality percentages were plotted versus log concentrations on logarithmic probit paper to obtain the corresponding regression mortality lines. The concentrations required to give $50 \%$ mortality (LC50) were estimated from the established regression lines (Jyoti and
Brewer, 1999). Each concentration test included 3 replicates each of 24 larvae (72 larvae/ concentration, 432 larvae /treatment).

Biological studies: $1^{\text {st }}$ instar larvae were treated in the same manner with the determined LC50 to study the effect of the entomopathogenic fungus $B$. bassiana and Biofly on certain biological aspects of the mushroom fly. Five replicates of $1^{\text {st }}$ instar larvae (40 larvae/replicate) were used for each compound. Larval and pupal mortalities, their durations, weight and moth emergence were recorded. The experiments were carried out under laboratory conditions of $23 \pm 1 \mathrm{C}^{\circ}$ and $80 \pm 5 \mathrm{RH}$.

\section{Statistical analysis}

ANOVA was performed using SAS software program.

\section{RESULTS AND DISCUSSION}

\section{Bioeffect of an isolates of the entomopathogenic fungus $B$. bassiana and Biofly on mushroom fly B. ocellaris larvae}

Results in Table (1) show the mortality percentage of $1^{\text {st }}$ instar larvae of mushroom fly after treatment with different concentrations of B. bassiana. The tested $B$. bassiana had a great efficacy against mushroom fly larvae. Also results indicate that the mortality rates increased with the increase of the concentration used and the period after treatment.

The corrected mortality percentages after 3 days for S1 isolate treatment ranged from $8.9 \%$ using the lowest concentration $\left(10^{2}\right.$ conidia $\left./ \mathrm{ml}\right)$, to $38.82 \%$ using the highest concentration $\left(10^{6}\right.$ conidia/ml). As treatment, the corrected percentages of mortality ranged from 4.3 to $29.34 \%$ for the lowest and highest concentrations, respectively for Biofly. These percentages increased to 50.6, and $19.06 \%$ after 7 days of treatment for S1 and bio fly, respectively. In contrast, the mortality percentages recorded for the highest concentration $\left(10^{6}\right.$ conidia/ml $)$ were $82.06,64.61 \%$ after 7 days, for the treatment with $\mathrm{S} 1$ and bio fly) respectively. Also the highest cumulative mortality (85.06, $69.6 \%$ ) was recorded after 14 days of treatment with $10^{6}$ conidia $/ \mathrm{ml}$ of (S1, biofly) respectively Table (1). The concentration mortality lines are graphically illustrated in Figs. (1 and 2) and showed a positive relationship between larval mortality and the concentrations used. It is worth 
Table 1. Corrected mortality percentages for the $1^{\text {st }}$ instar of mushroom fly Bradysia ocellaris larvae treated with an isolate (S1) of the entomopathogenic fungus Beauveria bassiana and Biofly

\begin{tabular}{|c|c|c|c|c|c|c|}
\hline \multirow{3}{*}{$\begin{array}{c}\text { Treatment } \\
\text { Isolate(S1) }\end{array}$} & \multicolumn{6}{|c|}{ Mean of corrected mortality $\%$} \\
\hline & \multicolumn{2}{|l|}{$\begin{array}{c}\text { Concentration } \\
\text { conidia/ml }\end{array}$} & \multicolumn{3}{|c|}{ Days after treatment } & \\
\hline & & 3 & 5 & 7 & 10 & 14 \\
\hline & $10^{+2}$ & 8.9 & 32.86 & 50.6 & 56.7 & 56.7 \\
\hline & $10^{+3}$ & 16.4 & 40.27 & 53.70 & 64.12 & 64.12 \\
\hline & $10^{+4}$ & 31.26 & 58.21 & 68.66 & 71.65 & 71.65 \\
\hline & $10^{+5}$ & 37.27 & 61.11 & 73.14 & 76.04 & 76.04 \\
\hline & $10^{+6}$ & 38.82 & 67.13 & 82.06 & 82.06 & 85.06 \\
\hline LC50 & & & & $0.95 \times 10^{2}$ & $0.9 \times 10^{2}$ & \\
\hline $\mathrm{R}$ & & & & 0.52 & 0.55 & \\
\hline \multirow{6}{*}{ Bio fly* } & & & & & & \\
\hline & $10^{+2}$ & 4.3 & 14.6 & 19.06 & 24.89 & 24.8 \\
\hline & $10^{+3}$ & 7.30 & 17.58 & 26.37 & 29.3 & 29.34 \\
\hline & $10^{+4}$ & 14.6 & 26.37 & 30.8 & 33.79 & 33.79 \\
\hline & $10^{+5}$ & 13.18 & 35.16 & 45.5 & 48.4 & 48.4 \\
\hline & $10^{+6}$ & 29.34 & 47.03 & 64.61 & 69.6 & 69.6 \\
\hline LC50 & & & & $5.7 \times 10^{5}$ & $4.55 \times 10^{5}$ & \\
\hline $\mathrm{R}$ & & & & 0.83 & 0.79 & \\
\hline
\end{tabular}

*Biofly: Commercial protect of B.bassiana

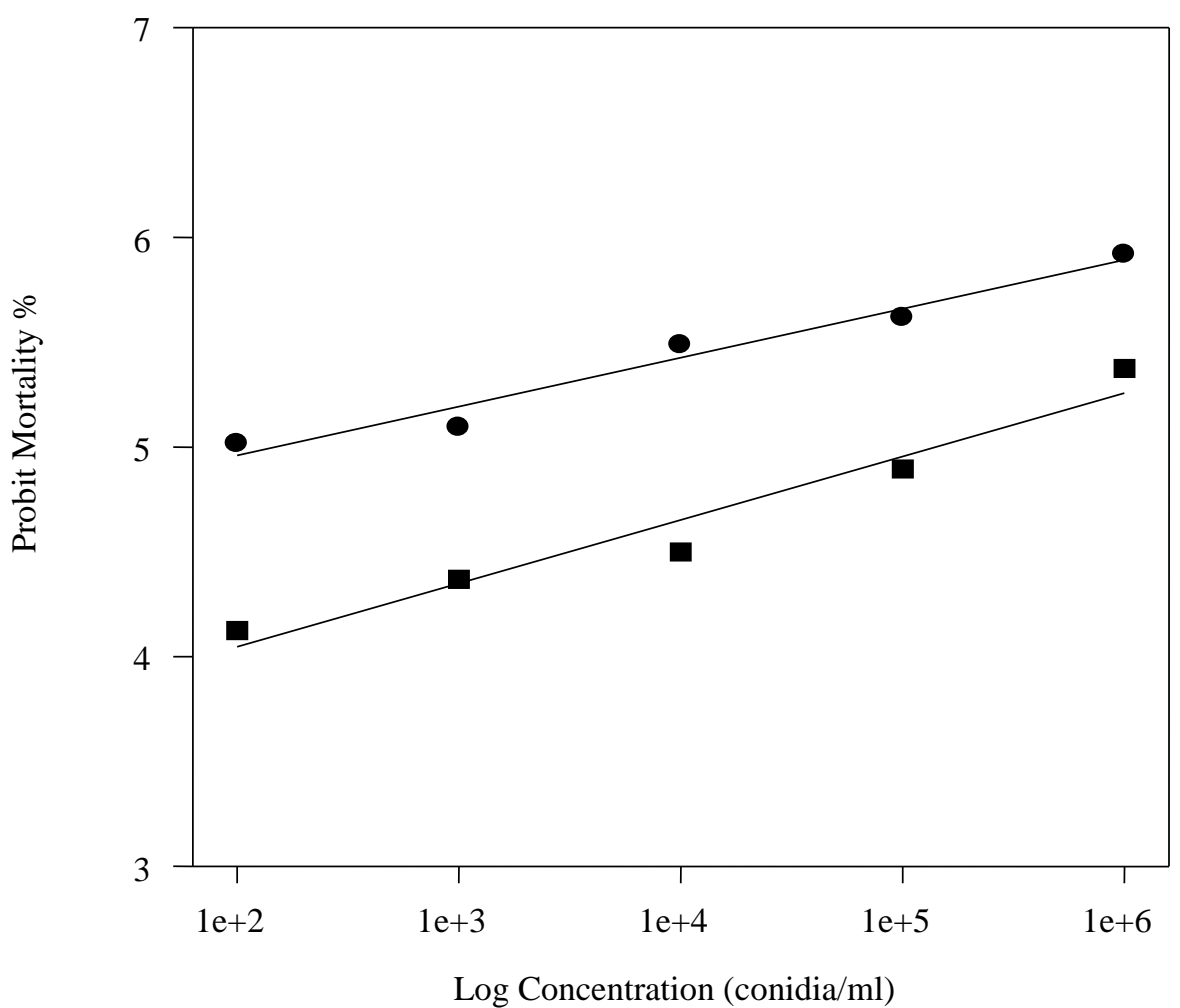

Fig.1. Toxicity lines of isolate S1 and Biofly on mushroom fly Bradysia ocellaris (Coms.) after 7 days following treatment 


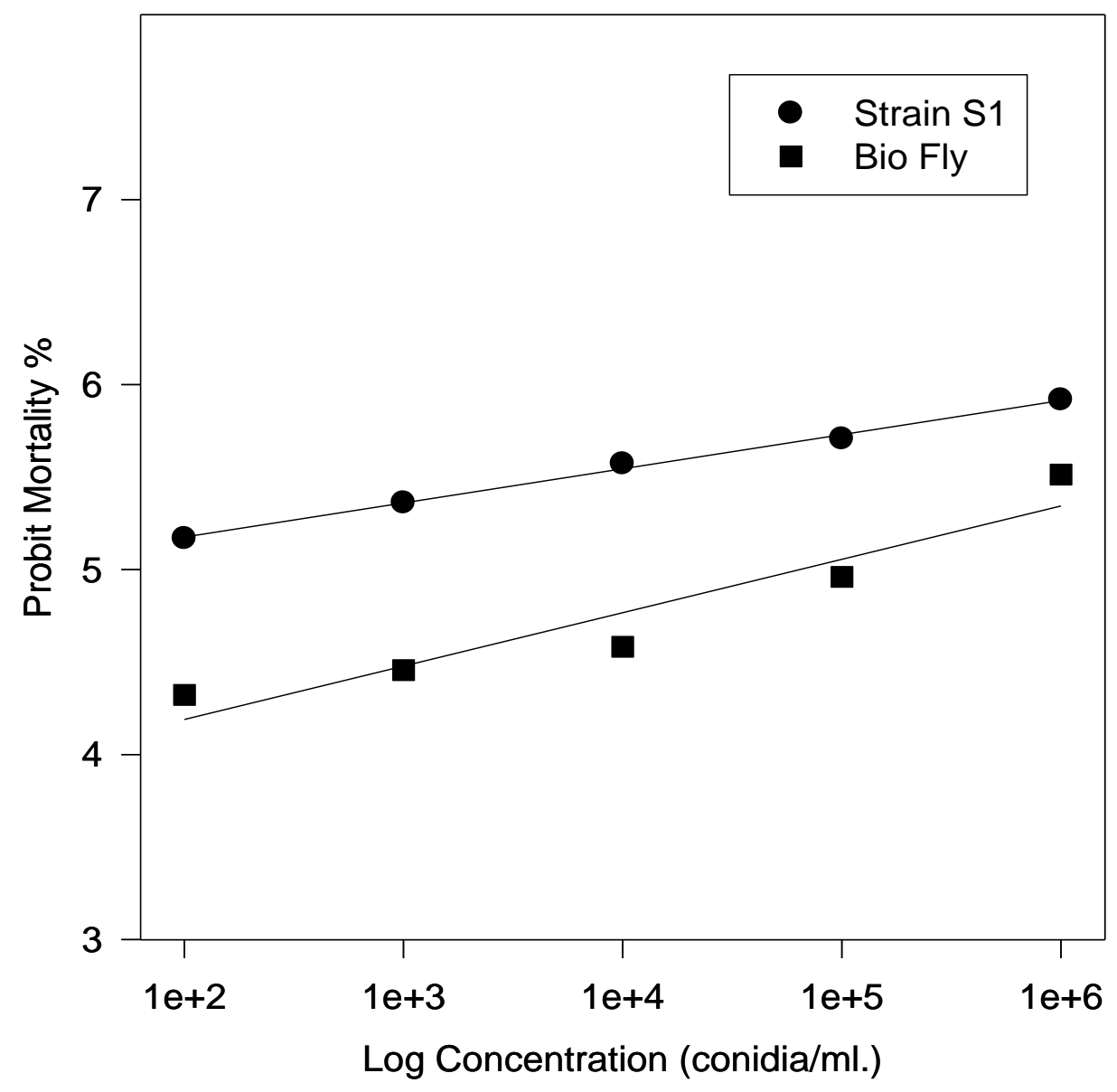

Fig. 2. Toxicity lines of isolate S1 and Bio fly on mushroom fly Bradysia ocellaris (Coms.) after 10 days following treatment

mentioning that the highest percentage of mortality occurred within the first 7days following treatment, while Larval mortality was relatively lower after 10 days (Table 1).

Effect of LC50 concentrations of an isolate of the entomopathogenic fungi $B$. bassiana and Biofly on larval, pupal and adult stages mortality of mushroom fly Bradysia ocellaris

Data in Table (2) show that the $\mathrm{LC}_{50}$ concentrations of the entomopathogenic B. bassiana and
Biofly which killed $50 \%$ of the treated larvae (after 7 days of treatment) had great effects on larval-pupal periods and adult longevity. Statistical analysis of the obtained larval-pupal periods and pupal weight revealed significant differences between treated and non-treated insects. The larval, pupal periods and adult longevity were 11.2, 5, 6.1 , days respectively (non-treated).Application of the entomopathogenic fungi B.bssiana and Biofly shortened larval and pupal development and adult longevity, which were $8.2,4.2,4.2-8.4,4.4,4.4$ days after treatment respectively. 
Table 2. Effect of treating $1^{\text {st }}$ instar larvae of the mushroom fly Bradysia ocellaris with LC $_{50}$ concentration of the Beauveria bassiana (Bals.) and Biofly on larval and pupal periods, pupal weight and adult longevity

\begin{tabular}{|ccccccc|}
\hline Treatment & $\begin{array}{c}\text { Mean larval } \\
\text { duration } \\
\text { period days }\end{array}$ & $\begin{array}{c}\text { Mean larval } \\
\text { weight } \\
(\mathrm{mg})\end{array}$ & $\begin{array}{c}\text { Mean pupal } \\
\text { duration } \\
\text { period (days) }\end{array}$ & $\begin{array}{c}\text { Mean pupal } \\
\text { weight } \\
(\mathrm{mg})\end{array}$ & $\begin{array}{c}\text { Mean } \\
\text { adults long } \\
(\text { days })\end{array}$ & $\begin{array}{c}\text { No of } \\
\text { pupal* }\end{array}$ \\
\hline S1 & $8.2^{\mathrm{b}}$ & $0.35^{\mathrm{b}}$ & $4.2^{\mathrm{b}}$ & $1.08^{\mathrm{b}}$ & $4.2^{\mathrm{b}}$ & $22.4^{\mathrm{b}}$ \\
Biofly & $8.4^{\mathrm{b}}$ & $0.29^{\mathrm{b}}$ & $4.4^{\mathrm{ab}}$ & $0.84^{\mathrm{b}}$ & $4.4^{\mathrm{b}}$ & $18.8^{\mathrm{c}}$ \\
control & $11.2^{\mathrm{a}}$ & $1.54^{\mathrm{a}}$ & $5^{\mathrm{a}}$ & $3.55^{\mathrm{a}}$ & $6.1^{\mathrm{a}}$ & $38.6^{\mathrm{a}}$ \\
CV & 6.8 & 21.1 & 12.7 & 12.9 & 13.4 & 9.4 \\
F & 35.2 & 105.7 & 2.6 & 204.7 & 12.6 & 88.7 \\
SE \pm & 0.4 & 0.02 & 0.33 & 0.06 & 0.43 & 6.2 \\
\hline LSD.50 & 0.87 & 0.21 & 0.8 & 0.32 & 0.91 & 3.4 \\
\hline
\end{tabular}

- No. of larvae $=40$ larvae.

\section{REFERENCES}

Abbott, W.S. (1925). A method of computing the effectiveness of an insecticide. J. Econ. Entomol., 18: $265-267$.

Ferron, P.; J. Fargues and G. Riba (1991). Fungi as microbial insecticides against pests. Handbook of Applied Mycology, Vol. 2, pp. 665-706, Arora, D.K.; L. Ajello and K.G. Mukerji, (eds.), M.Dekker Inc., New York.

Finley, R.J.; P.J. Wuest; D.J. Royse; R. Snetsinger; R. Tetrault and D.L. Rinker (1984). Mushroom flies - A review of biology and a systems approach for integrated control. Mushroom News 28: 240-246.

Finney, D.J. (1952). Probit Analysis. ( $3^{\text {rd }}$ Ed.), Cambridge Univ. Press, London.

Gillespie, A.T. (1988). Use of fungi to control pest of agricultural importance. Fungi in Biological Control Systems, pp.37-60, Burges, H. (ed.), Manchester University Press, London.

Gouge, D.H. and N.G.M. Hague (1994). Development of Steinernema feltiae (Steinernematidae:Nematoda) in Bradysia paupera (Sciaridae : Diptera). Bulletin IOBC/WPRS, 17:132135.

Ishitani, E.; T. Gotoh and T. Kawasaki (1997). Development of sticky light trap and attractiveness to mushroom infesting sciaridys, Lycoriella mali (Fitch) and Bradysia paupera Tuomikoski
(Diptera:Sciaridae). Jpn. J. Appl. Entomol. Zool. 41: 141-146. (In Japanese with English summary). Jess, S. and M. Kilpatrick (2000). An integrated approach to the control of Lycoriella solani (Diptera: Sciaridae) during production of the cultivated mushroom (Agaricus bisporus). Pest Manag. Sci. 56: 477-485.

Jyoti, J.L. and G.J. Brewer (1999). Median lethal concentration and efficacy of Bacillus thuringiensis against banded sunflower moth (Lepidoptera: tortricidae). Journal of Economic Entomology, 92(6): 1289-1291.

Malsam, O.; M. Kilian and R. Hain, (1998). Fungal insecticides. In: Fungal Biotechnologie, pp. 26-37, Anke, T. (ed.), Chapman and Hall, London.

Prior, C. (1990). The biological basis for regulating the release of microorganisms, with particular refernce to the use of fungi for pest control. Aspect of Applied Biology 24: 231-238.

Zimmerman, G. (1986). Insect pathogenic fungi as pest control agents, pp. 217-231. In: Franz, J.M. (ed.): Biological Plant and Health Protection. International Symposium of the Akademie der Wissenschaften und der Literature, Mains, November $15-17^{\text {th }}, 1984$, at Mains \& Darmstadt., Fortschritte der Zoologie, Gustav Fisher Verlag, Stuttgart, Germany. 